\title{
OPTICAL PLANAR WAVEGUIDE SENSOR BASED ON (Yb,Nb):RTP/RTP(001) SYSTEM FOR THE ESTIMATION OF METAL COATED CELLS
}

\author{
M.A. Butt ${ }^{1}$, E.S. Kozlova ${ }^{1,2}$, S.N. Khonina ${ }^{1,2}$, R.V. Skidanov ${ }^{1,2}$ \\ ${ }^{1}$ Samara National Research University, Samara, Russia \\ ${ }^{2}$ Image Processing Systems Institute - Branch of the Federal Scientific Research Centre "Crys- \\ tallography and Photonics" of Russian Academy of Sciences, Samara, Russia
}

\begin{abstract}
In this work, we demonstrated metal tagged cell counting based on planar waveguide with the help of a visible light at $633 \mathrm{~nm}$ with TM polarization and calculated the output power in relation with the density of cells placed on the waveguide.
\end{abstract}

Keywords: $\mathrm{RbTiOPO}_{4},(\mathrm{Yb}, \mathrm{Nb}): \mathrm{RTP} / \mathrm{RTP}$, reactive ion etching, planar waveguide, metal- tagged cell counting.

Citation: Butt MA, Kozlova ES, Khonina SN, Skidanov RV. Optical planar waveguide sensor based on $(\mathrm{Yb}, \mathrm{Nb}): \mathrm{RTP} / \mathrm{RTP}(001)$ system for the estimation of metal coated cells. CEUR Workshop Proceedings 2016; 1638: 16-23. DOI: 10.18287/1613-0073-2016-1638-16-23

\section{Introduction}

$\mathrm{RbTiOPO}_{4}$ (RTP) belongs to $\mathrm{KTiOPO}_{4}$ (KTP) family of nonlinear optical crystals. These crystals are orthorhombic, with the space group Pna ${ }_{21}$. These crystals are well known for their large electro-optical coefficients, high nonlinear coefficients and low dielectric constants which make them attractive for electro-optic applications such as modulators and Q-switches [1]. These electro-optic properties makes RTP compounds as attractive material for integrated optical applications for the fabrication of active and passive devices. Traditionally in KTP family, the devices are fabricated by ion diffusion techniques where gradient refractive index contrast is achieved [2]. Planar optical waveguides are already been performed on epitaxial layers (Yb,Nb):RTP on RTP and these systems possess a stepped refractive index contrast, for guiding light in the near infra red (NIR) and visible range. Reactive ion etching (RIE) is widely used for structuring different dielectric materials such as $\mathrm{SiO}_{2}$ and $\mathrm{LiNbO} 3$ [3]. However, the use of this technique in the KTP family of compounds has been not largely explored.

In the past years, KTP is recognized as a finer material for guiding wave optics. KTP has shown to have attractive properties for SHG of the Nd:YAG and other Nd:doped 
lasers, sum and difference frequency mixing and optical parametric oscillation processes. KTP thin films offer a practical and cost effective alternative to single crystals with enhanced design and capability for integrated optic applications. Nowadays the literature related to integrated photonics in RTP is scarce as compared to KTP. Over past few years, research has been conducted on RTP in order to explore its properties for the use in integrated photonics. First exploratory research to obtain optimum conditions for RIE in (Yb,Nb):RTP epitaxial layer to obtain a channel waveguide with a height around 1 microns was demonstrated [5]. Recently, some work related to RTP waveguides based on ion exchange, RIE and direct laser writing were demonstrated [5-7]. We believe that, this report is the first demonstration of the waveguide sensor to count cells based on RTP waveguides.

In this paper, we demonstrated the practical use of $(\mathrm{Yb}, \mathrm{Nb}): \operatorname{RTP} / \mathrm{RTP}(001)$ planar waveguide for cell counting based on BeamProp (Rsoft Design Group) simulations. Waveguides are optical structures capable of guiding light by total internal reflection. Waveguides have been widely used in telecommunication industry for more than 25 years; and were recently employed as a biosensor for detection and diagnosis [8-17]. Generally, in optical waveguides, the electromagnetic field of the guided light extends beyond the waveguide core, known as evanescent field which has been exploited in several ways as sensing mechanism [17-19]. When this evanescent field interacts with the overlaying particles and changes its refractive index, the effective refractive index of the guided mode changes which provides the sensing mechanism. We investigated the effect of evanescent field on the metal tagged objects for sensing purpose as shown in Figure 1.

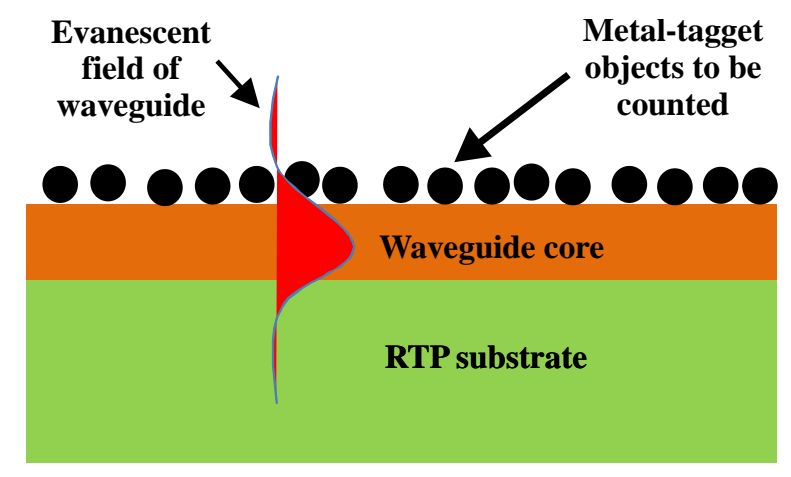

Fig. 1. Evanescent wave interacting with the metal tagged objects placed on the top of buried planar waveguide

In our proposed design, we used a planar waveguide of RTP/(Yb,Nb):RTP/RTP(001) system. The design is optimized by varying core and cladding parameters for efficient sensing. In our approach, a visible light of $633 \mathrm{~nm}$ TM polarized light as an input, because these waveguides can only guide TM polarization [6]. When the light encounters labeled objects lying above the waveguide, such as cells, the intensity in the waveguide attenuated. The attenuation is proportional to the number of cells placed on the waveguide. There are several practical applications of these waveguides for the 
biological and chemical sensing [14,20-21]. We have conducted 3-D simulations by using BeamProp software in order to provide the optimized design with high sensitivity.

\section{Proposed Fabrication Steps}

Although this article is based on simulation results of the waveguide sensor, we hereby provide the scheme for the fabrication of such waveguide for future development. Chromium metal layer deposited on RTP (001) substrate will act as a hard mask during physical etching. Direct laser writing or conventional photolithography is used to provide patterns on positive photoresist. The sample is then developed and chemically etched by commercially available chromium etchant. Now, the sample is ready for RIE. The optimized recipe for etching can be found in [4]. Once, the groove are obtained in the substrate, the epitaxial layer of $(\mathrm{Yb}, \mathrm{Nb})$ :RTP is grown by using liquid phase epitaxy (LPE) method. The epitaxial layer is polished until it is only present in the groove. The end faces perpendicular to propagation direction are polished and coupled with laser light.

\section{Analysis of waveguide output power for periodic cell distribution}

In this section of the paper, we have analyzed the effect of various concentration of cells periodically placed on the waveguide versus the output power for the purpose of cell counting. Three different core heights of 2, 3 and $4 \mu \mathrm{m}$ are used to examine the sensitivity of the waveguide sensor. Additionally, we have used a cladding index of 1.35 to represent the aqueous solution that can be expected in the microfluidic channel.

The refractive index of RTP substrate and (Yb,Nb):RTP epitaxial at $633 \mathrm{~nm}$ was obtained from [6]. To simulate the effect of metal tagged objects, we placed $4 \times 4 \times 4$ $\mu \mathrm{m}$ aluminium metal cells and used a complex index of refraction and absorption coefficient of 1.3387 and 7.2975 at $633 \mathrm{~nm}$ respectively. The metal coated objects were placed on the waveguide at a distance of $3000 \mu \mathrm{m}$ from the input of the waveguide till $7000 \mu \mathrm{m}$ and the total power in the waveguide is analysed. The power stays constant in the waveguide and starts to decrease when encounters the metal coated cells and then remains constant in the absence of the cells. The concentration/number of cells to be placed on the waveguide for the purpose of analysis are calculated according to Table 1.

Table 1. The Ratio of Concentration and the Number of Cells to the Total area of placement equal to $4 \cdot 105(100 \times 4000)$

\begin{tabular}{lllllll}
\hline Concentration, \% & $\mathbf{0 . 0 1}$ & $\mathbf{0 . 0 3}$ & $\mathbf{0 . 0 5}$ & $\mathbf{0 . 0 7}$ & $\mathbf{0 . 1}$ & $\mathbf{0 . 1 5}$ \\
\hline Number & 250 & 750 & 1250 & 1750 & 2500 & 3750 \\
\hline
\end{tabular}

In order to simulate the propagation along z-axis, we used Implicit Crank-Nicolson scheme with a grid size of $0.4 \mu \mathrm{m}$ in $\mathrm{X}, \mathrm{Y}$ and $\mathrm{Z}$ and by applying the Simple Trans- 
parent Boundary Condition (TBC). The Gaussian pulse was choosen for launch condition. The weight and height of launch field are equal the weight and height of the waveguide core. The cells were periodically placed on a waveguide with a special dynamic array tool by using the formula (1).

$T_{\text {dist }}=\sqrt{\frac{S_{\text {total }}}{C_{\text {cells }}}}$,

where $T_{\text {dist }}$ is the periodicity of cells, $S_{\text {total }}$ is the total area which is covered by cells, $C_{\text {cells }}$ is cell concentration.
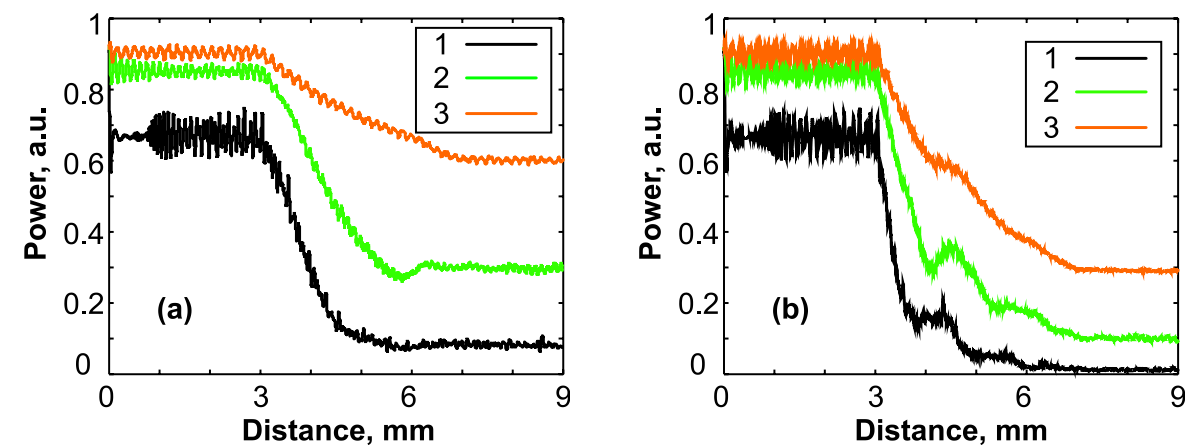

Fig. 2. Power vs distance for waveguide with the core thickness of 2 (line 1),3 (line 2) and 4 (line 3 ) microns for $5 \%$ cells (a) and $15 \%$ cells (b)

Figure 2 (a) and (b) represents the power decay versus the propagation distance in the presence of periodic cell distribution placed on waveguide at $5 \%$ and $15 \%$ respectively. TM polarized light at $633 \mathrm{~nm}$ was used for these simulations. It can be seen that, the input power in the waveguide with $2 \mu \mathrm{m}$ core thickness has some oscillations and has less propagation power as compared to waveguide with core 3 and $4 \mu \mathrm{m}$ marked in green and red respectively. It shows that, core height of $2 \mu \mathrm{m}$ is not able to support the modes properly at $633 \mathrm{~nm}$. Therefore, we can choose core height of 3 or $4 \mu \mathrm{m}$ for proper light transmission.

\section{Analysis of waveguide output power for random cell distribution}

When the cells are placed in aqueous solution over the waveguide, their distribution cannot be controlled. Cells can have distributions such as periodic, random or even they can make clusters. Therefore, in this work, we have focused on the random cell distribution.

We performed some simulations by keeping in mind, the behavior of micro particles placed in aqueous solution over the waveguide. Therefore, we randomly distributed the cells on the cladding layer at a distance of $3000 \mu \mathrm{m}$ from the input of the waveguide till $7000 \mu \mathrm{m}$. These simulations were performed for $1 \%$ of cell concentration 
with, uniform cell distribution, random cell distribution and clusters. Figure 3a shows ordinary distribution of cells (random or periodic distribution) and Figure $3 \mathrm{~b}$ represents distribution with clusters of cells. To explain clusters we use various heights of the cells as explained in Table 2 .
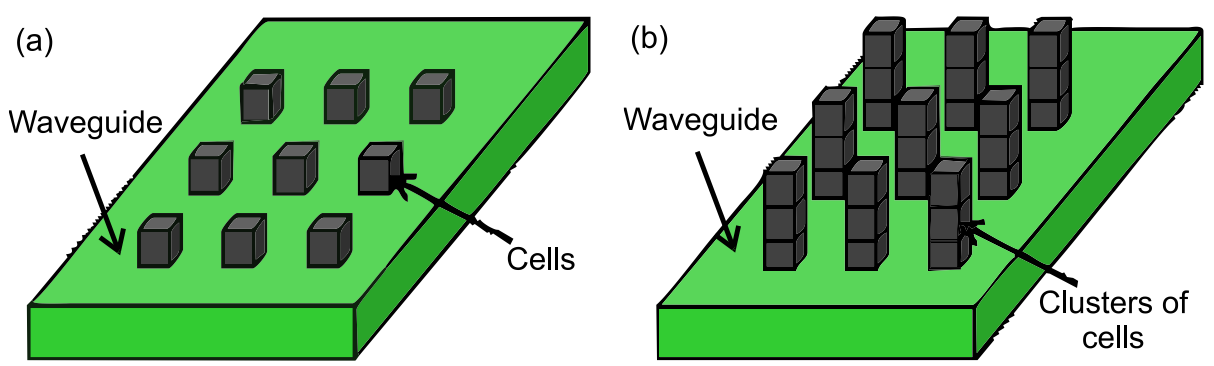

Fig. 3. Scheme of cell's distribution on waveguide: ordinary (a) and with clusters (b)

Table 2. Details of cells distribution used in simulation

\begin{tabular}{|c|c|c|c|c|c|c|c|c|}
\hline \multirow[t]{2}{*}{ № } & \multirow{2}{*}{$\begin{array}{l}\text { Dist. } \\
\text { type }\end{array}$} & \multicolumn{5}{|c|}{ Cell sizes $(\mu \mathrm{m})$} & \multirow{2}{*}{$\begin{array}{l}S_{\text {total }}, \\
\boldsymbol{\mu m}^{2}\end{array}$} & \multirow{2}{*}{$\begin{array}{l}V_{\text {total }}, \\
\boldsymbol{\mu m}^{3}\end{array}$} \\
\hline & & $4 \times 4 \times 4$ & $10 \times 10 \times 4$ & $10 \times 10 \times 10$ & $15 \times 15 \times 4$ & $15 \times 15 \times 15$ & & \\
\hline 1 & Uni. & 250 & - & - & - & - & 4000 & 16000 \\
\hline 2 & Rand. & 250 & - & - & - & - & 4000 & 16000 \\
\hline 3 & Rand. & 201 & 49 & - & - & - & 8116 & 32464 \\
\hline 4 & Rand. & 176 & 49 & - & 25 & - & 13341 & 53364 \\
\hline 5 & $\begin{array}{l}\text { Rand. } \\
\text { cluster }\end{array}$ & 176 & - & 49 & - & 25 & 13341 & 144639 \\
\hline
\end{tabular}

Figure 4 shows the power versus distance for the cell concentration of $1 \%$ placed on the waveguide with core height of $3 \mu \mathrm{m}$.

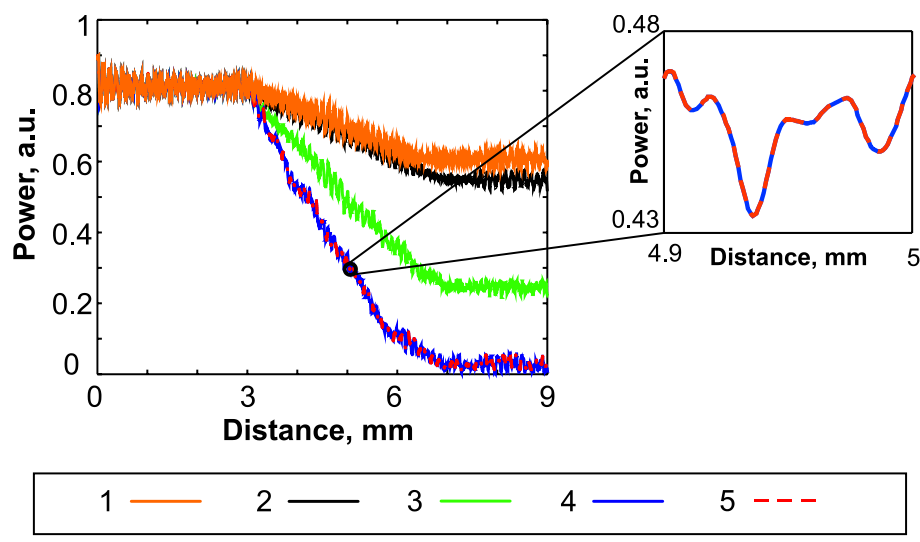

Fig. 4. Power vs distance for $1 \%$ cells concentrations in case of uniform (line 1)and random (line 2) distribution of cells with the same size, random distribution of cells with different size (line 3-4), random distribution of cluster of cells (line 5) 
In case of random (line 2) and uniform cell distribution (line 1), even though, the contact area of cells with waveguide is equal but the sensitivity of the waveguide is much higher for random cells distribution. As the cell size increases, the contact area with the waveguide increases, therefore we can observe a drastic fall of power for 3-5 lines according to their contact areas. The line 5 represents the power decay in the waveguide with larger total volume of the cells $\left(V_{\text {total }}\right)$ placed on it. The volume of the cells is much larger than other cells distribution under consideration that it can be treated as a cluster of cells placed on the waveguide. But the total area of contact of the cells with the waveguide is equal for line 4 and line 5; therefore, the power decay response is overlapping. This fact suggests that, the cell counting depends on the contact area of the cells with the waveguide.

In order to understand the results obtained in Figure 4, we have analyzed the evanescent field travelling outside the core at a height of $0.1 \mu \mathrm{m}$. As it can be seen from Figure 5a, the field is not homogeneous throughout the propagation distance. This can highly effects the interaction of the field with the cells that is why when the cells with different distributions are placed over the waveguide, the output power response is different (line 1 and 2) as shown in Figure 4. We have also studied the behavior of evanescent field on single cells as well as clusters of cells. For this reason, we have plotted the evanescent field at a distance of $1 \mu \mathrm{m}$ over the waveguide as shown in Figure 5b. It can be seen that the field intensity in Figure 5b is close to zero which means that evanescent field only interacts with the first layer of cells. Therefore, line 4 and 5 has same output response regardless of different heights as shown in Figure 4.

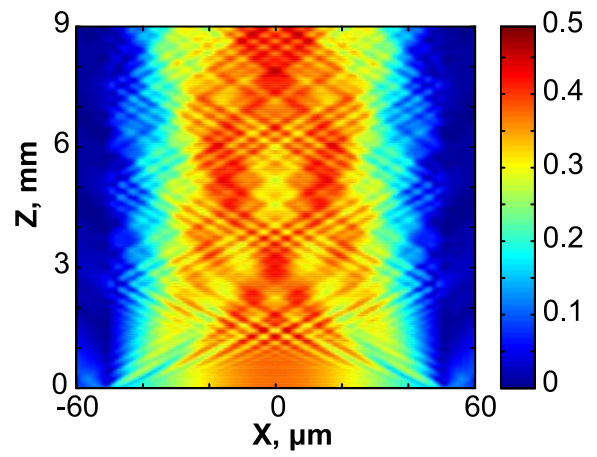

(a)

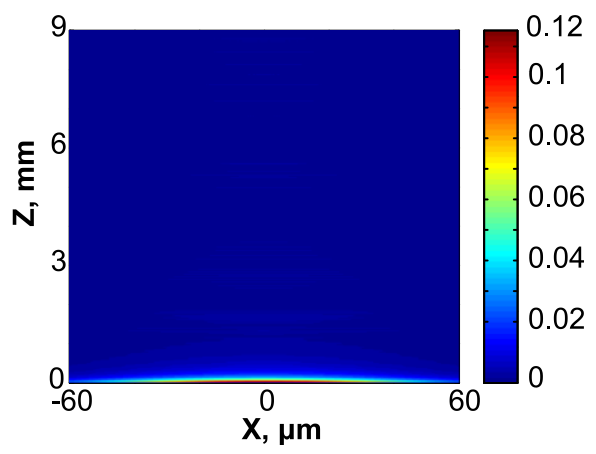

(b)

Fig. 5. Amplitude of evanescent field on the distance $0.1 \mu \mathrm{m}$ (a) and $1 \mu \mathrm{m}$ (b) from waveguide

\section{Conclusion}

In summary, we have proposed a method of using planar buried waveguides based on $(\mathrm{Yb}, \mathrm{Nb}): \mathrm{RTP} / \mathrm{RTP}(001)$ system to estimate metal-tagged objects encountering evanescent field of the waveguide. These proposed waveguides can be used for counting metal-tagged cells or other molecules that can scatter energy from the waveguide. In this work, we have studied different distribution of cells over the waveguide. The 
analysis of the evanescent field determines its non-homogeneity; therefore each cell distribution has its own impact on the output power. However, the contact area of the cells with the waveguide is the vital factor for cell counting. This technique can work with virtually any metal-tagged cells; we expect this technology to impact on cell counting applications in military medicine, in disaster settings, and in rural healthcare.

\section{Acknowledgements}

We acknowledge funding from the Russian Foundation for Basic Research (RFBR) (16-07-00990,14-29-07133), the Ministry of Education and Science of the Russian Federation (and also SP-4375.2016.5).

\section{References}

1. Satyanarayan MN, Deepthy A, and Bhat HL. Potassium titanyl phosphate and its isomorphs: growth, properties and applications. Critical Review Solid State and Materials Sciences, 1999; 24(2): 103-191.

2. Risk WP. Fabrication and characterization of planar Ion-exchanged KTiOPO4 waveguides for frequency doubling. Applied Physics Letters, 1991; 58(19): 19-21.

3. Volkov AV, Moiseev OYu, Poletaev SD. Precision laser recording on a molybdenum films for diffractive microrelief formation. Computer Optics, 2013; 37(2): 220-225. [In Russian].

4. Choudhary A, Cugat J, Pradeesh K, Sole R, Diaz F, Aguilo M, Chong HMH and Shepherd DP. Single-mode rib waveguides in $(\mathrm{Yb}, \mathrm{Nb})$ : RbTiOPO4 by reactive ion etching. Journal of Physics D: Applied Physics, 2013; 46(14): 145108.

5. Butt MA, Pujol MC, Sole R, Rodenas A, Lifante G, Wilkinson JS, Aguilo M, and Diaz F. Channel waveguides and Mach-Zehnder structures on RbTiOPO4 by Cs+ ion exchange. Optical Material Express, 2015; 5(5): 1183-1194.

6. Butt MA, Sole R, Pujol MC, Rodenas A, Lifante G, Choudhary A, Murugan GS, Shepherd DP, Wilkinson JS, Aguilo M, and Diaz F. Fabrication of Y-splitters and Mach-Zehnder Structures on $(\mathrm{Yb}, \mathrm{Nb})$ : RTiOPO4/RbTiOPO4 Epitaxial layers by Reactive Ion Etching. Journal of Lightwave Technology, 2015; 33(9): 1863-1871.

7. Butt MA, Nguyen H-D, Rodenas A, Romero C, Moreno P, Vazuez de Aldana JR, Aguilo M, Sole RM, Pujol MC, and Diaz F. Low-repitition rate femtosecond laser writing of optical waveguides in KTP crystals: analysis of anisotropic refractive index changes. Optics Express, 2015; 23(12): 15343-15355.

8. Huang L, Guo Z. Biosensing in a microelectrofluidic system using optical whisperinggallery mode spectroscopy. Biomicrofluidics, 2011; 5: 034114.

9. Li XC, Wu J, Liu AQ, Li ZG, Soew YC, Huang HJ, Xu K, and Lin JT. A liquid waveguide based evanescent wave sensor integrated onto a microfluidic chip. Applied Physics Letters, 2008; 93: 193901-193903.

10. Taitt CR, Anderson GP, and Ligler FS. Evanescent wave Flourescence biosensors. Biosens Bioelectron, 2005; 20(12): 2470-2487.

11. Xu F, Datta P, Wang H, Gurung S, Hashimoto M, Wei S, Goettert J, McCarley RL, and Soper SA. Polymer microfluidic chips with integrated waveguides for reading microarray. Analytical Chemistry, 2007; 79(23): 9007-9013. 
12. Sheridan AK, Stewart G, Ur-Reyman H, Suyal N, and Uttamchandani D. In-Plane Integration of Polymer Microfluidic Channels with Optical waveguides- A Preliminary Investigation. IEEE Sensors Journal, 2009; 9(12): 1627-1632.

13. Myers FB and Lee LP. Innovations in optical microfluidic technologies for point-of-care diagnostics. Lab on a Chip, 2008; 8(12): 2015-2031.

14. Hofmann O, Voirin G, Niedermann P, Manz A. Three dimensional microfluidic confinement for efficient sample delivery to biosensor surfaces. Application to immunoassays on planar optical waveguides. Analytical Chemistry, 2002; 74(20): 5243-5250.

15. Burke CS, Stranik O, McEvoy HM, and MacCraith BD. Optical Chemical Sensors. Netherlands: Springer, 2006. 193 p.

16. Strilets TS, Kotlyar VV, Nalimov AG. Simulation of waveguide modes in multilayer structures. Computer Optics, 2010; 34(4): 487-493. [In Russian].

17. Garcia D, Ghansah I, LeBlanc J, and Butte MJ. Counting cells with a low-cost integrated microfluidics-waveguide sensor. Biomicrofluidics, 2012; 6(1): 014115-014118.

18. Cunningham BT, and Laing L. Microplate-based, label free detection of biomolecular interactions: applications in proteomics. Expert Review of Proteomics, 2006; 3(3): 271-281.

19. Kadomina EA, Bezus EA, Doskolovich LL. Resonant photonic-crystal structures with a diffraction grating for refractive index sensing. Computer Optics, 2016; 40(2): 164-172. [In Russian]. DOI: 10.18287/2412-6179-2016-40-2-164-172.

20. Friis P, Hoppe K, Leistiko O, Mogensen KB, Hubner J, and Kutter JP. Monolithic integration of microfluidic channels and optical waveguides in silica. Applied Optics, 2001; 40(36): 6246-6251.

21. Puyol M, Salinas I, Garces I, Villuendas F, Llobera A, Dominguez C, and Alonso J. Improved Integrated Waveguide Absorbance Optodes for Ion-Selective Sensing. Analytical Chemistry, 2002; 74(14): 3354-3361.

22. Duveneck GL, Abel AP, Bopp MA, Kresbach GM, and Ehrat M. Planar waveguides for ultra-high sensitivity of the analysis of nucleic acids. Analytica Chimica Acta, 2002; 469(1): 49-61. 